\title{
Does methylene blue reduce adhesion during the healing process after tendon repair?
}

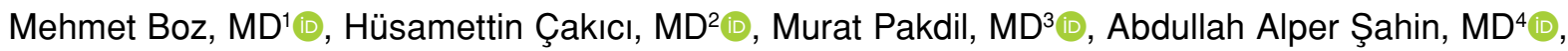

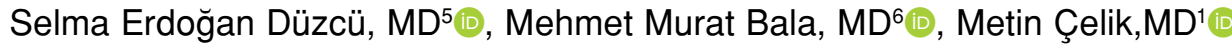 \\ 1'Department of Orthopedics and Traumatology, Malatya Training and Research Hospital, Malatya, Turkey \\ ${ }^{2}$ Department of Orthopedics and Traumatology, Abant Izzet Baysal University Faculty of Medicine, Bolu, Turkey \\ ${ }^{3}$ Department of Mechanical Engineering, Abant Izzet Baysal University Faculty of Engineering, Bolu, Turkey \\ ${ }^{4}$ Department of Orthopedics and Traumatology, Ordu University Training and Research Hospital, Ordu, Turkey \\ ${ }^{5}$ Department of Pathology, Abant Izzet Baysal University Faculty of Medicine, Bolu, Turkey \\ ${ }^{6}$ Department of Orthopedics and Traumatology, Trabzon Health Sciences University Kanuni Training and Research Hospital, Trabzon, Turkey
}

The hand is the most active, least protected part of the upper extremity and therefore frequently injured.$^{[1,2]}$ Hand injuries constitute approximately $20 \%$ of all patients admitted to the emergency room. Flexor tendon injuries occur frequently because tendons are close to the skin surface. ${ }^{[3]}$ Tendon injuries can occur with a sharp object such as glass and knife, or the injury can originate at the place where tendons are attached to the bone as a result of blunt trauma that may occur in more strength-based sports such as football, basketball, wrestling, and arm wrestling. ${ }^{[4]}$ In developed and industrialized countries, flexor tendon injuries occur mostly after work accidents, whereas in developing countries with low socioeconomic levels, they occur as a result of knife or glass incision due to arguments and quarrels. ${ }^{[5]}$ In Turkey, flexor tendon injuries generally occur as a result of penetrating stab wounds ${ }^{[6,7]}$ Among hand injuries, flexor tendon cuts are most common between the ages of 20-45 years and often accompanied by other soft tissue injuries. ${ }^{[6]}$ In

Received: March 03, 2020

Accepted: April 15, 2020

Published online: June 18, 2020

Correspondence: Mehmet Boz, MD. Malatya Eğitim ve Araştırma Hastanesi Ortopedi ve Travmatoloji Kliniği, 44090 Yeşilyurt,

Malatya, Türkiye.

E-mail: dr_memoz@hotmail.com

Doi: $10.5606 /$ ehc. 2020.74405

Citation: Boz M, Cakıcı H, Pakdil M, Sahin AA, Erdoğan Düzcü $S$, Bala MM ,Çelik M. Does methylene blue reduce adhesion during the healing process after tendon repair? Jt Dis Relat Surg 2020;31(2):246-254.

\section{ABSTRACT}

Objectives: This study aims to biomechanically and histopathologically investigate the effects of methylene blue (MB) on preventing postoperative adhesion in chickens undergoing fullthickness flexor tendon incision.

Materials and methods: This study was performed between June 2017 and June 2018 on Hubbard JA 57 type chickens (age, 6 months; weight, $2.2 \pm 0.3 \mathrm{~kg}$ ). Sixty-four tendons were studied in 32 chickens, including 16 in the control group and 16 in the experimental group. The second and third finger flexor digitorum profundus tendons of the left foot of each chicken were repaired primarily after a full-thickness incision approximately $1 \mathrm{~cm}$ proximal to the distal adhesion area. In the control $(\mathrm{n}=32)$ and experimental groups $(\mathrm{n}=32), 0.25 \mathrm{~mL}$ of normal saline and $0.25 \mathrm{~mL}$ of $1 \% \mathrm{MB}$ solutions were applied locally to the surgical site, respectively. The operated limb was immobilized using a circular cast. 16 chickens were randomly selected in each group and examined at the fourth week, and the remaining 16 chickens were examined at the sixth week. Thirty-two of these tendons were evaluated using the Tang histopathological adhesion classification system, and the other 32 were evaluated with a biomechanical pull system.

Results: Adhesion was found to be less in the experimental group compared to the control group at the end of the fourth and sixth weeks both histopathologically and biomechanically. Furthermore, adhesion was significantly less in the experimental group at the end of the sixth week compared to the fourth week both histopathologically and biomechanically.

Conclusion: Histopathological and biomechanical results show that MB, which has anti-inflammatory, antiseptic, antimicrobial and antioxidant effects, reduces adhesion during the healing process after tendon repair. We think that local MB application, particularly in surgeries performed after this type of injury, will be beneficial on early rehabilitation and functional results.

Keywords: Chicken flexor tendon, flexor tendon adhesion, methylene blue, tendon healing. 
the literature, it has been reported that flexor tendon injuries are frequently seen in zones II-V. ${ }^{[7]}$ Hand injuries present with a broad spectrum from simple soft tissue trauma to amputation. Such injuries cause functional losses and limited daily activities. Therefore, the primary objective is that the patient returns to his/her work and social life as early as possible with little functional loss. ${ }^{[1-3]}$ Tendon healing consists of stages of inflammation, proliferation and remodeling, respectively. While the amount of type III collagen is higher in the first phases, type I collagen dominance is observed in the last stage of the healing period. ${ }^{[8,9]}$

"Methylene blue (MB)", which is a basic substance, is a dark green crystalline powder without scent. When it dissolves in normal saline (NS) or pure water, it becomes dark blue. With its xanthine oxidase effect, MB competes with molecular oxygen used in electron transfer and prevents the formation of free oxygen radicals. ${ }^{[10]}$ Recent studies have shown that MB decreases the levels of inflammatory cytokines such as tumor necrosis factor-alpha (TNF- $\alpha$ ), interleukin (IL)-1, and IL-6 and shows anti-inflammatory and antioxidant effects as well as reducing the harmful effects of nitric oxide (NO) ${ }^{[11]}$ It is thought that MB will both accelerate the tendon healing process and reduce the adhesion that may occur in the postoperative period, particularly with its anti-inflammatory, antioxidant and antimicrobial effect. ${ }^{[10,11]}$ To the best of our knowledge, there is no study in the literature investigating the effect of $\mathrm{MB}$ on flexor tendon healing. When experimental studies on flexor digitorum profundus tendon adhesion are examined, it is seen that chicken models are frequently used as subjects. ${ }^{[12,13]}$ We preferred to use chickens for reasons such as low cost and the adequate accommodation conditions in the animal laboratory where we carried out the study. Therefore, in this study, we aimed to biomechanically and histopathologically investigate the effects of $\mathrm{MB}$ on preventing postoperative adhesion in chickens undergoing full-thickness flexor tendon incision.

\section{MATERIALS AND METHODS}

This study was performed at the Experimental Animal Production and Care Unit (Vivarium) Laboratory of Abant Izzet Baysal University between June 2017 and June 2018. Hubbard JA 57 type chickens $(n=32$; age, 6 months; weight, $2.2 \pm 0.3 \mathrm{~kg}$; Abant Izzet Baysal University Faculty of Medicine, Animal Laboratory, Bolu, Turkey) were placed in cages and exposed to daily light cycle. Room temperature was kept at $22-24^{\circ} \mathrm{C}$. During the experiment period, chickens were fed with standard feed. The experiment was performed using 64 deep flexor tendons of the chickens. Animal experiments were carried out in the Experimental Animal Production and Care Unit (Vivarium) Laboratory of Abant İzzet Baysal University. Ethics committee approval was obtained on 19.04.2017 (no.2017/181).

The 32 chickens were randomly divided into two groups, with 16 chickens per group. The left foot second and third finger flexor digitorum profundus tendons of each chicken were repaired primarily after a full thickness incision approximately $1 \mathrm{~cm}$ proximal to the distal adhesion site. $0.25 \mathrm{~mL}$ NS and $0.25 \mathrm{~mL} 1 \% \mathrm{MB}$ solutions were applied locally to the surgical site in the control group $(n=32)$ and the experimental group $(n=32)$, respectively. The operated limbs were immobilized by circular cast. Sixteen chickens were randomly selected in each group and examined in the fourth week, and the remaining 16 chickens were studied in the sixth week. A total of 64 tendons were examined. Thirtytwo of these tendons were evaluated with Tang histopathological adhesion classification system and the other 32 were evaluated with biomechanical pull system.

The surgical approach was performed by the same surgeon under the anesthetic effect induced by intramuscular administration of $20 \mathrm{mg} / \mathrm{kg}$ ketamine (ketamine hydrochloride, Ketalar ${ }^{\circledR}$; EWL Eczacibaşı Warner Lambert Istanbul, Turkey) to the pectoral muscles. The adequacy of anesthesia was checked by limb pull response. During the operation period, ketamine was applied again as needed to ensure the depth of anesthesia. Appropriate anesthesia depth was created. The left foot of the animal in the control group was brushed and cleaned with Isosol ${ }^{\circledR}$ scrub (Merkez Lab. Ilaç San. ve Tic. A.Ş., Istanbul, Türkiye) and the chicken was placed in the supine position on the operation table. Surgical site was stained with povidone-iodine (Batticon ${ }^{\circledR}$, Adeka İlaç Sanayi ve Ticaret A.Ş, Istanbul, Turkey) and closed with sterile drapes. Then, a longitudinal skin incision of approximately $2 \mathrm{~cm}$ was performed from the distal volar face to the proximal on the second and third fingers of the chickens, skin and subcutaneous tissue were passed by blunt dissection and the flexor digitorum profundus tendon was reached. The tendon sheath was opened longitudinally and the tendon transverse incision line was determined. The proximal and distal parts of the determined incision line were fixed with insulin injector needle and the incision was performed transversely with scalpel no. 11. The released tendon ends were repaired 

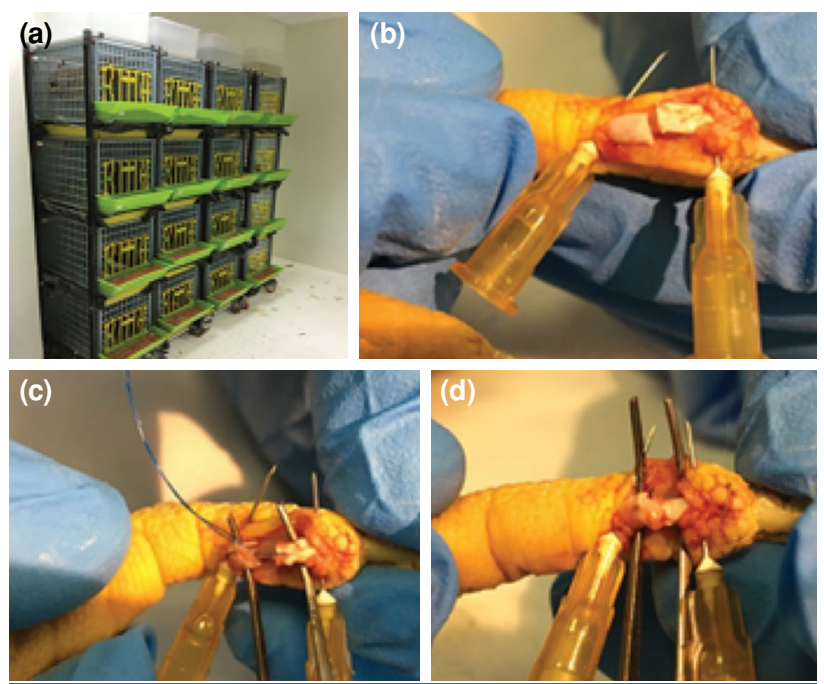

FIGURE 1. (a) Housing conditions of experimental animals. (b) Image after transverse incision of tendon. (c) Modified Kessler method. (d) Repair with modified Kessler method.

with $5 / 0$ round monofilament polypropylene suture (Propilen ${ }^{\circledR}$, Doğsan, Tibbi Malzeme San. A.Ş, Istanbul, Turkey) using the modified Kessler method. $0.25 \mathrm{~mL}$ NS was applied locally to the surgical site, and the skin was primary sutured with a $4 / 0$ round monofilament polypropylene suture (Propilen ${ }^{\circledR}$, Doğsan Tibbi Malzeme San. A.Ş, Istanbul, Turkey). The same procedures were performed in the experimental group; $0.25 \mathrm{~mL} \mathrm{1 \%} \mathrm{MB} \mathrm{solution} \mathrm{(MB,}$ Merck, Istanbul, Turkey) was applied locally and the skin was primary sutured. Due to total tenotomy, the chickens were immobilized with a circular leg cast (Figures 1 and 2).

For histopathological evaluation, 16 tendons from each group were examined in the fourth and sixth weeks after surgery. For histomorphological examination of 32 chicken deep flexor tendons, foot tissues cut from the knee level were fixed in $10 \%$ formaldehyde solution. After one day of formaldehyde solution fixation, tissues were taken into $10 \%$ formic acid and kept in formic acid for 10 days. Horizontal sections were taken from the tendon repair site of
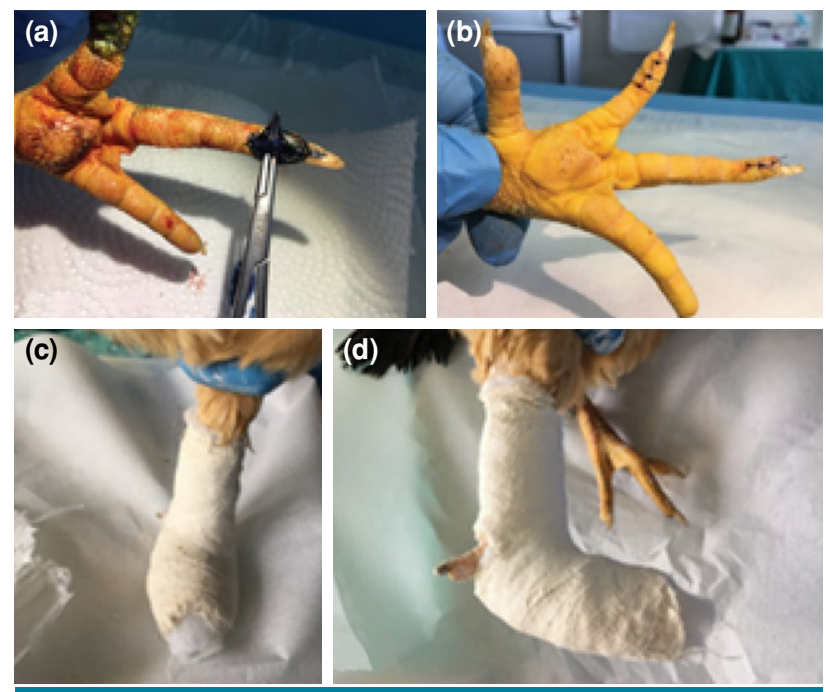

FIGURE 2. (a) Methylene blue injection after tendon repair. (b) Primary skin suturing after tendon repair. (c) Circular cast front view. (d) Circular cast lateral view.

the second and third fingers, and the tissue was followed-up and embedded in paraffin. Three $\mu \mathrm{m}$ thick sections were taken from the prepared paraffin blocks and stained with hematoxylin-eosin. Sections were evaluated by a LEICA DM LB2 light microscope (Leica Microsystems Wetzlar GmbH, Wetzlar, Germany) and photographed with the INFINITY 3 ANALYZE Release 6.5 imaging system (Lumenera Inc., Ottawa, ON, Canada).

Peritendinous adhesion formation, repair quality, and presence of a peritendinous cavity were examined with Tang scoring system histopathologically. ${ }^{[14]}$ Samples were graded from one to five in terms of adhesion and presence of peritendinous space (Table I).

Biomechanical tests were performed at the Mechanics Division of the Mechanical Engineering Department of the Faculty of Engineering, Abant İzzet Baysal University. In order to compare the biomechanical properties, left lower extremities of eight chickens were cut from the knee level at the

\begin{tabular}{lc}
\multicolumn{1}{c|}{$\begin{array}{l}\text { TABLE I } \\
\text { Tang adhesion scoring system }\end{array}$} & Score \\
\hline Histopathological scoring in terms of adhesion severity & 1 \\
\hline No adhesion, peritendinous space preserved. & 2 \\
Minimal adhesion, peritendinous space preserved in many areas. & 3 \\
Moderate adhesion, peritendinous space preserved in more than 50\% of tendon circumference. \\
Severe adhesion, obliteration in the peritendinous space in more than 50\% of the tendon circumference. & 4 \\
Tendon completely attached to the surrounding tissue. & 5 \\
\hline
\end{tabular}


end of fourth and sixth weeks, and the proximal parts of the second and third finger deep flexor tendons were marked with $2 / 0$ vicryl. These were placed in storage containers in pads impregnated with isotonic serum. Biomechanical pull tests were carried out in Universal Mechanical Test Device with Zemic Load Cell (Zemic USA Inc., Downey, CA, USA) using a tendon pull apparatus designed by us.

In order to evaluate the finger movement of the tendons effectively, the samples cut from the knee level were separately drilled with a $1.8 \mathrm{~mm}$ drill at two points from the middle of the tibia in a lateral plan, without any contact with the tendons, with $1.5 \mathrm{~cm}$ transverse distance between each other, and without moving the tendons. Two specially designed Kirschner wires were passed through these holes. These were then placed in a biomechanical test device and fixed (Figure 3).

The finger was pulled until flexion motion occurred. The pulling speed of the samples was also set at $4 \mathrm{~mm} /$ minute (mean $4 \mathrm{~mm} /$ minute) in each sample. The movement values obtained from the sensors of the mechanical test device and the force values obtained from the $15 \mathrm{~kg}$ (147.015 Newton [N]) load cell were recorded by the device's own software.
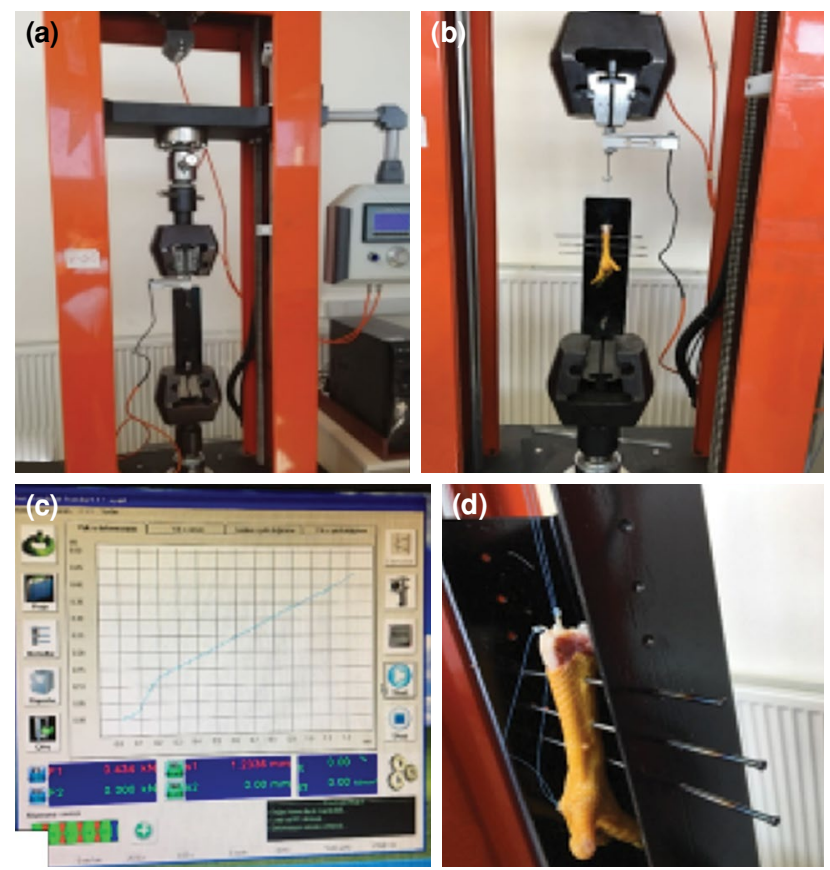

FIGURE 3. (a) Mechanical test device and tendon pull apparatus (Universal Mechanical Test device, Zemic Load Cell). (b) Tendon sample placed in mechanical test device. (c) Sample image showing movement-force screen of device. (d) Tendon placed in tendon pulling apparatus we designed.

\section{Statistical analysis}

The IBM SPSS version 22.0 software (IBM Corp., Armonk, NY, USA) was used for data analysis. Normality was tested by Shapiro-Wilk test. It was seen that histopathological data were not normally distributed $(\mathrm{p}<0.05)$, whereas biomechanical data were normally distributed ( $p>0.05)$. Mann-Whitney $\mathrm{U}$ test was used for comparing histopathological data. Histopathological data were presented as minimum-median-maximum. Student t-test was used to compare biomechanical values. Biomechanical data were presented as arithmetic mean and standard deviation. A $p$ value $<0.05$ was considered statistically significant in all analyses.

\section{RESULTS}

No complications were observed in the surgical site of the chickens. Table II shows the scores of each tendon in the experimental and control groups in

\begin{tabular}{|c|c|c|}
\hline \multicolumn{3}{|c|}{$\begin{array}{r}\text { TABLE II } \\
\text { week histopathologica }\end{array}$} \\
\hline \multirow[b]{2}{*}{ Tendon } & Control group $(n=8)$ & MB group $(n=8)$ \\
\hline & Degree of adhesion & Degree of adhesion \\
\hline 1 & 5 & 4 \\
\hline 2 & 5 & 4 \\
\hline 3 & 5 & 4 \\
\hline 4 & 5 & 4 \\
\hline 5 & 5 & 4 \\
\hline 6 & 5 & 4 \\
\hline 7 & 5 & 5 \\
\hline 8 & 5 & 4 \\
\hline B: Methyle & & \\
\hline
\end{tabular}

\begin{tabular}{|c|c|c|}
\hline \multicolumn{3}{|c|}{$\begin{array}{r}\text { TABLE III } \\
\text { Sixth week histopathological }\end{array}$} \\
\hline \multirow[b]{2}{*}{ Tendon } & Control group $(n=8)$ & MB group $(n=8)$ \\
\hline & Degree of adhesion & Degree of adhesion \\
\hline 1 & 4 & 3 \\
\hline 2 & 4 & 3 \\
\hline 3 & 4 & 2 \\
\hline 4 & 3 & 2 \\
\hline 5 & 4 & 3 \\
\hline 6 & 4 & 3 \\
\hline 7 & 4 & 3 \\
\hline 8 & 4 & 3 \\
\hline
\end{tabular}




\begin{tabular}{|c|c|c|c|c|}
\hline \multicolumn{5}{|c|}{ TABLE IV } \\
\hline \multirow[b]{3}{*}{ Groups } & \multicolumn{4}{|c|}{ Tang adhesion score } \\
\hline & \multicolumn{2}{|c|}{ Fourth week } & \multicolumn{2}{|c|}{ Sixth week } \\
\hline & Mean & Min-Max & Mean & Min-Max \\
\hline Experimental $(\mathrm{n}=8)$ & 4 & $4-5$ & 3 & $2-3$ \\
\hline Control $(n=8)$ & 5 & $5-5$ & 4 & $3-4$ \\
\hline$p$ value & \multicolumn{2}{|c|}{0.002} & \multicolumn{2}{|c|}{0.001} \\
\hline
\end{tabular}

fourth week according to the Tang adhesion scoring system. Table III shows the scores of each tendon in the experimental and control groups in sixth week according to the Tang adhesion scoring system.

As seen in Table IV, the median Tang adhesion score of the experimental group in fourth week was 4 and that of the control group was 5 . The median Tang adhesion score of the experimental group was significantly lower compared to the control group $(\mathrm{p}<0.05)$. In sixth week, the median Tang adhesion score of the experimental group was 3 and that of the control group was 4 . The median Tang adhesion score of the experimental group was significantly lower $(\mathrm{p}<0.05)$.

As seen in Figure 4, in the fourth week, there was a dense fibro-collagenous tissue around the tendon in the control group and severe adhesion was observed. There was no peritendinous space. In the experimental group, although the adhesion around the tendon was intense, some peritendinous space was formed. In the sixth week, there was focal peritendinous space around the tendon in the control group, but there
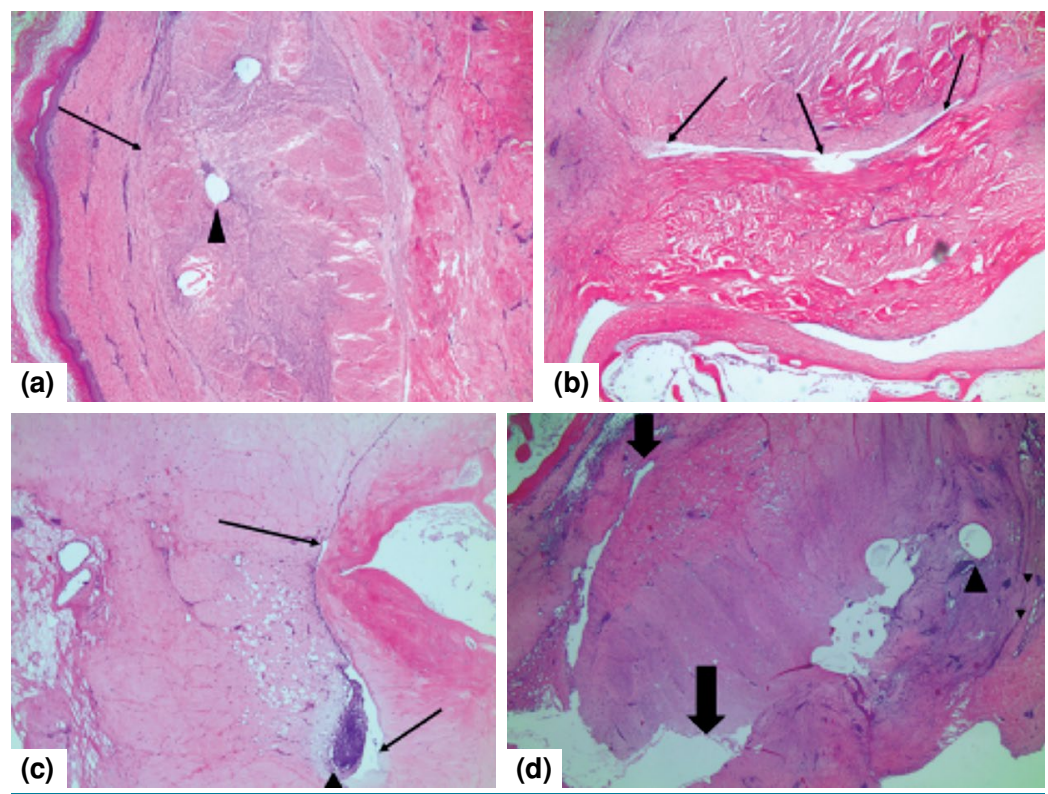

FIGURE 4. (a) Control group, (H-Ex40): Peritendinous space is obliterated, with marked adhesion, there is inflammation and suture material (arrow adhesion area, arrow head suture material and inflammation around it). (b) Experimental group, ( $\mathrm{H}-\mathrm{E} \times 40)$ : Although adhesion is observed, peritendinous space has begun to become apparent (arrows peritendinous space). (c) Control group (H-E x100): Moderate adhesion, inflammation around suture material (arrows peritendinous space, arrow head inflammation). (d) Experimental group, ( $\mathrm{H}-\mathrm{E} \times 40)$ : Peritendinous space is preserved in most areas, suture material is present with minimal adhesion (thin arrows minimal adhesion, thick arrows preserved peritendinous space, arrowhead inflammation around suture material). 


\begin{tabular}{|c|c|c|c|c|}
\hline \multicolumn{5}{|c|}{$\begin{array}{l}\text { TABLE V } \\
\text { mechanical evaluation results }\end{array}$} \\
\hline \multirow[b]{3}{*}{ Tendon } & \multicolumn{4}{|c|}{ Force generated against $4 \mathrm{~mm}$ movement (Newton) } \\
\hline & \multicolumn{2}{|c|}{ MB group $(n=8)$} & \multicolumn{2}{|c|}{ Control group $(n=8)$} \\
\hline & $2^{\text {nd }}$ finger & $3^{\text {rd }}$ finger & $2^{\text {nd }}$ finger & $3^{\text {rd }}$ finger \\
\hline 1 & 15.558 & 20.944 & 17.726 & 21.032 \\
\hline 2 & 13.900 & 23.425 & 16.078 & 34.599 \\
\hline 3 & 5.562 & 16.166 & 15.375 & 35.816 \\
\hline 4 & 11.124 & 18.254 & 16.078 & 27.114 \\
\hline
\end{tabular}

\begin{tabular}{|c|c|c|c|c|}
\hline \multirow[b]{4}{*}{ Tendon } & \multicolumn{3}{|c|}{ TABLE VI } & Sixth week biomechanical evaluation results \\
\hline & \multicolumn{4}{|c|}{ Force generated against $4 \mathrm{~mm}$ movement (Newton) } \\
\hline & \multicolumn{2}{|c|}{ MB group $(n=8)$} & \multicolumn{2}{|c|}{ Control group $(n=8)$} \\
\hline & $2^{\text {nd }}$ finger & $3^{\text {rd }}$ finger & $2^{\text {nd }}$ finger & $3^{\text {rd }}$ finger \\
\hline 1 & 4.954 & 14.950 & 5.650 & 16.078 \\
\hline 2 & 4.600 & 8.603 & 9.908 & 17.638 \\
\hline 3 & 4.954 & 4.600 & 4.257 & 10.604 \\
\hline 4 & 5.209 & 14.253 & 7.298 & 12.596 \\
\hline
\end{tabular}

was severe adhesion and moderate adhesion in one sample. In the experimental group, peritendinous space had already begun to form around the tendon. Adhesion was less than $50 \%$ in some cases and more than $50 \%$ in some cases. Significantly less adhesion was observed in the sixth week compared to the control group, and the peritendinous space was better preserved (Figure 4).

In the biomechanical evaluation of the groups at the fourth and sixth weeks, although the amount of force generated against $4 \mathrm{~mm}$ movement of the tendon was lower in the experimental group compared to the control group, the difference between the groups was not significant $(p>0.05)$. This shows us that the force used to move the

\begin{tabular}{|c|c|c|}
\hline \multicolumn{3}{|c|}{$\begin{array}{c}\text { TABLE VII } \\
\text { biomechanical eva }\end{array}$} \\
\hline \multirow{3}{*}{ Groups } & \multicolumn{2}{|c|}{ Biomechanical values (Newton) } \\
\hline & $2^{\text {nd }}$ finger & $3^{\text {rd }}$ finger \\
\hline & Mean $\pm S D$ & Mean \pm SD \\
\hline Experimental & $11.536 \pm 4.382$ & $19.697 \pm 3.162$ \\
\hline Control & $16.314 \pm 0.997$ & $29.640 \pm 6.909$ \\
\hline$p$ value & 0.078 & 0.040 \\
\hline
\end{tabular}

tendon by the same distance was less in the $\mathrm{MB}$ group (Tables V and VI).

Table $\mathrm{V}$ shows the data obtained from the biomechanical pull system at fourth and sixth weeks for each tendon in $\mathrm{MB}$ and control groups.

As seen in Table VII, in fourth week, the biomechanical value obtained for the second finger was $11.536 \pm 4.382$ Newton $(\mathrm{N})$ in the experimental group and $16.314 \pm 0.997 \mathrm{~N}$ in the control group. Although the biomechanical value of the experimental group was lower than the control group, the difference between the groups was not significant ( $p>0.05)$. The biomechanical value obtained for the third finger was $19.697 \pm 3.162 \mathrm{~N}$ in the experimental

\begin{tabular}{|c|c|c|}
\hline \multicolumn{3}{|c|}{$\begin{array}{l}\text { TABLE VIII } \\
\text { mechanical evaluation results }\end{array}$} \\
\hline \multirow{3}{*}{ Groups } & \multicolumn{2}{|c|}{ Biomechanical values (Newton) } \\
\hline & $2^{\text {nd }}$ finger & $3^{\text {rd }}$ finger \\
\hline & Mean $\pm S D$ & Mean \pm SD \\
\hline Experimental & $4.929 \pm 0.250$ & $10.601 \pm 4.907$ \\
\hline Control & $6.778 \pm 2.428$ & $14.229 \pm 3.206$ \\
\hline$p$ value & 0.225 & 0.262 \\
\hline
\end{tabular}


group and $29.640 \pm 6.909 \mathrm{~N}$ in the control group. The biomechanical value of the experimental group was significantly lower $(\mathrm{p}<0.05)$.

As seen in Table VIII, in sixth week, the biomechanical value obtained for the second finger was $4.929 \pm 0.250 \mathrm{~N}$ in the experimental group and $6.778 \pm 2.428 \mathrm{~N}$ in the control group. Although the biomechanical value of the experimental group was lower than the control group, the difference between the groups was not significant $(p>0.05)$. The biomechanical value obtained for the third finger was $10.601 \pm 4.907 \mathrm{~N}$ in the experimental group and $14.229 \pm 3.206 \mathrm{~N}$ in the control group. Although the biomechanical value of the experimental group was lower, the difference between the groups was not significant $(\mathrm{p}>0.05)$.

\section{DISCUSSION}

Hand injuries constitute approximately $20 \%$ of the patients applying to the emergency room. Flexor tendon injuries occur very often because the tendon is close to the skin surface. ${ }^{[3]}$ Occupational accidents constitute an important part of flexor tendon injuries all over the world. Patients are affected psychologically, socially and functionally due to the inability to use the damaged limb for a certain period after flexor tendon repair. Although the normal physiological healing process of the damaged tendon is completed, adhesion and contractures become an important functional problem for both surgeons and patients, further increasing the patients' limitations. For this reason, there are many previous and ongoing experimental and clinical studies to minimize the complications that can be seen after tendon repair ${ }^{[15,16]}$ Many drugs and medical materials are used to prevent postoperative adhesion in tendon damage.

When experimental studies on tendon are examined, it is seen that rat and chicken models are frequently used as subjects. We preferred to use chicken for reasons such as low cost, similarity with human flexor tendon, and adequate and sufficient accommodation conditions in the animal laboratory where the study was conducted.

As a result of the damage, fibrotic scar tissue forms during tendon healing. The mechanical strength of this scar tissue is weaker compared to the normal tendon. The primary objective for both patient and surgeon in tendon healing is achieving the desired level of functional results. Many biomaterials and drugs have been tested in various studies to avoid complications such as adhesion and functional loss in tendon healing and to make the tendon stronger after the healing process is completed. ${ }^{[16,17]}$ Growth factors and cytokines were used for this purpose and skeletal structures were created from cells containing fibroblasts and these factors and cytokines were exogenously applied. ${ }^{[18]}$ In an experimental study published in 2011, intraperitoneal MB solution treatments were more effective according to vitamin $\mathrm{E}$ in preventing the formation of intraabdominal adhesion in a rat uterine horn model. ${ }^{[19]}$

Numerous experimental studies related to tendon healing have been presented and intrinsic and extrinsic healing mechanisms have been described in detail. ${ }^{[20]}$ Studies have shown that the adhesion that occurs during tendon healing is due to fibroblastic activity that is effective in extrinsic healing. ${ }^{[20]}$ Extrinsic healing begins with cells moving from the tendon sheath to the healing area after chemotaxis. This situation also suppresses intrinsic healing and causes fibrosis. For this reason, it is necessary to prevent inflammation, fibroblast proliferation and excessive collagen synthesis to prevent adhesion. ${ }^{[21]}$

When the literature was reviewed, no study was found on the effect of anti-inflammatory, antioxidative, antifibroblastic and anti-adhesion properties of $\mathrm{MB}$ on flexor tendon healing. Methylene blue has been examined by other surgical branches and its adhesion preventing effects have been supported by many studies. Neagoe et al. $^{[2]}$ retrospectively examined the effect of local MB on preventing postoperative peritoneal adhesion development on 20 patients undergoing abdominal surgery and reported positive results. Kalayc1 et al. ${ }^{[23]}$ investigated the effects of MB on preventing postoperative adhesion in rats with peritonitis, and MB was shown to prevent peritoneal adhesions.

Dinç et al. ${ }^{[1]}$ used MB in rats in an experimental colitis model induced with acetic acid, and observed antioxidant effect of $\mathrm{MB}$ by reducing the harmful effects of NO and anti-inflammatory effect by suppressing TNF- $\alpha$, IL-1 beta ( $\beta$ ), and IL-6 levels. Privistirescu et al. ${ }^{[2]}$ reported that $\mathrm{MB}$ applied to rats with diabetes mellitus had an antioxidative effect in alleviating endothelial dysfunction and reducing endothelial oxidative stress. In a study conducted by McCartney et al. ${ }^{[25]}$ to evaluate the efficacy, dose and reliability of $\mathrm{MB}$ in vasoplegic syndrome, it was found that $\mathrm{MB}$ inhibited $\mathrm{NO}$ synthase and showed antioxidative effect by limiting $\mathrm{NO}$ formation. There are many studies on the importance of physical therapy and rehabilitation to prevent postoperative adhesion. "Passive bending and loosening" exercises or "passive flexion-active extension" splints that do 
the same job can be used as the safest method for early mobilization in repairs after flexor tendon damage. ${ }^{[26,27]}$

Since adhesion after flexor tendon surgery causes serious loss of function, studies aimed at preventing postoperative tendon adhesion have continued. In an experimental study using local interferon- $\alpha$, interferon- $\beta$ and 5-fluorouracil, 5-fluorouracil was shown to prevent adhesion with anti-inflammatory effect. ${ }^{[28]}$ In another study, local vitamin E analogue was shown to reduce postoperative adhesion by antioxidant and antifibrotic effects in an experimental chicken model with flexor digitorum profundus tendon injury. ${ }^{[12]}$ Reduced postoperative adhesion was shown in another study where collagen-elastin matrix was used to prevent postoperative adhesion in an experimental rabbit model undergoing flexor tendon repair. ${ }^{[18]}$

We did not find any study in the literature investigating the effect of $\mathrm{MB}$ on adhesion after chicken flexor tendon injury. We proposed that $\mathrm{MB}$, particularly with its anti-inflammatory, antioxidant, antifibrotic effect, would both speed up the tendon healing process and reduce the adhesion that may occur in the postoperative period. ${ }^{[10,11]}$ In the present study, the effect of $\mathrm{MB}$ on adhesion after flexor tendon injury was examined. No local or systemic side effects of MB applied locally during the study period were observed. Histopathological and biomechanical data were used for evaluation. In light of the histopathological evaluations, we found that $\mathrm{MB}$ increased peritendinous space and decreased postoperative adhesion by decreasing inflammation compared to the control group. Biomechanically, the average amount of force required for the $0-4 \mathrm{~mm}$ movement of the tendon was $15.616 \mathrm{~N}$ in the experiment group and $22.977 \mathrm{~N}$ in the control group in fourth week, and $7.765 \mathrm{~N}$ in the experiment group (MB) and $10.503 \mathrm{~N}$ in the control group in sixth week. Based on these data, it was determined that the tendons in the experimental group treated with MB moved more comfortably than the tendons in the control group in the fourth and sixth weeks.

This study has some limitations. It would have been preferable if we had performed trials with the chicken's unused flexor tendon before the biomechanical test. Since we performed both histopathological and biomechanical work, we may have obtained more significant results biostatistically if we had a larger sample size.

In conclusion, based on the results of the biostatistical analysis performed in light of the histopathological and biomechanical data obtained, it was seen that biomechanically, the movement was more comfortable in the experimental group compared to the control group. This observation was supported by the data obtained, while it was not statistically significant. In the histopathological evaluation, it was determined that the amount of adhesion was lower in the experimental group compared to the control group and this difference was statistically significant. Considering histopathological and biomechanical data, less adhesion was detected in the experimental group in the fourth and sixth weeks. Taking these data into consideration, we believe that the rehabilitation process will be more reliable and loss of labor after repair will be decreased since the use of $M B$ in tendon repairs reduces the adhesion that occurs in the tendon healing process. Local application of $\mathrm{MB}$ in terms of systemic complications and its cost-effectiveness and availability are important advantages. We believe that more comprehensive studies on this topic should be conducted on larger subject groups.

\section{Declaration of conflicting interests}

The authors declared no conflicts of interest with respect to the authorship and/or publication of this article.

\section{Funding}

The authors received no financial support for the research and/or authorship of this article.

\section{REFERENCES}

1. Ootes D, Lambers KT, Ring DC. The epidemiology of upper extremity injuries presenting to the emergency department in the United States. Hand (N Y) 2012;7:18-22.

2. Giustini M, de Leo A, Leti Acciaro A, Pajardi G, Mamo C, Voller F, et al. Incidence estimates of hand and upper extremity injuries in Italy. Ann Ist Super Sanita 2015;51:305-12.

3. Clark DP, Scott RN, Anderson IW. Hand problems in an accident and emergency department. J Hand Surg Br 1985;10:297-9.

4. Griffin M, Hindocha S, Jordan D, Saleh M, Khan W. An overview of the management of flexor tendon injuries. Open Orthop J 2012;6:28-35.

5. Erazo JP, Sabongi RG, Moares VY, Santos JBGD, Faloppa F, Belloti JC. Penetrating Wounds of the Upper Extremity - Prevalence and Etiology. Rev Bras Ortop (Sao Paulo) 2019;54:134-9.

6. Jackson LL. Non-fatal occupational injuries and illnesses treated in hospital emergency departments in the United States. Inj Prev 2001;7:i21-6.

7. Kitsis CK, Wade PJ, Krikler SJ, Parsons NK, Nicholls LK. Controlled active motion following primary flexor tendon repair: a prospective study over 9 years. J Hand Surg $\mathrm{Br}$ 1998;23:344-9.

8. Zhang AY, Chang J. Tissue engineering of flexor tendons. Clin Plast Surg 2003;30:565-72. 
9. Buckwalter JA, Glimcher MJ, Cooper RR, Recker R. Bone biology. I: Structure, blood supply, cells, matrix, and mineralization. Instr Course Lect 1996;45:371-86.

10. Salaris SC, Babbs CF, Voorhees WD 3rd. Methylene blue as an inhibitor of superoxide generation by xanthine oxidase. A potential new drug for the attenuation of ischemia/ reperfusion injury. Biochem Pharmacol 1991;42:499-506.

11. Dinc S, Caydere M, Akgul G, Yenidogan E, Hücümenoglu $S$, Rajesh M. Methylene Blue inhibits the inflammatory process of the acetic acid-induced colitis in the rat colonic mucosa. Int Surg 2015. [Online ahead of print]

12. Lee YW, Fu SC, Mok TY, Chan KM, Hung LK. Local administration of Trolox, a vitamin $\mathrm{E}$ analog, reduced tendon adhesion in a chicken model of flexor digitorum profundus tendon injury. J Orthop Translat 2016;10:102-7.

13. Hung LK, Fu SC, Lee YW, Mok TY, Chan KM. Local vitamin- $C$ injection reduced tendon adhesion in a chicken model of flexor digitorum profundus tendon injury. J Bone Joint Surg [Am] 2013;95:e41.

14. Bhavsar D, Shettko D, Tenenhaus M. Encircling the tendon repair site with collagen-GAG reduces the formation of postoperative tendon adhesions in a chicken flexor tendon model. J Surg Res 2010;159:765-71.

15. Khanna A, Friel M, Gougoulias N, Longo UG, Maffulli N. Prevention of adhesions in surgery of the flexor tendons of the hand: what is the evidence? Br Med Bull 2009;90:85-109.

16. Şahin AA, Özturan KE, Çıraklı A, Yılmaz F, Boz M, Kizilay $\mathrm{H}$. The effect of pentoxifylline on Achilles tendon healing in tenotomized rabbits. Eklem Hastalik Cerrahisi 2019;30:259-66.

17. Chan BP, Fu SC, Qin L, Rolf C, Chan KM. Pyridinoline in relation to ultimate stress of the patellar tendon during healing: an animal study. J Orthop Res 1998;16:597-603.

18. Wichelhaus DA, Beyersdoerfer ST, Gierer P, Vollmar B, Mittlmeier $\mathrm{T}$. The effect of a collagen-elastin matrix on adhesion formation after flexor tendon repair in a rabbit model. Arch Orthop Trauma Surg 2016;136:1021-9.
19. Yildiz H, Durmus AS, Simsek H, Yaman I. The comparison of methylene blue and vitamin $\mathrm{E}$ in prevention of abdominal postoperative adhesion formation in rat uterine horn models: Biochemical and histopathologic evaluation. Acta Cir Bras 2011;26:51-7.

20. Gelberman RH, Manske PR, Vande Berg JS, Lesker PA, Akeson WH. Flexor tendon repair in vitro: a comparative histologic study of the rabbit, chicken, dog, and monkey. J Orthop Res 1984;2:39-48.

21. James R, Kesturu G, Balian G, Chhabra AB. Tendon: biology, biomechanics, repair, growth factors, and evolving treatment options. J Hand Surg Am 2008;33:102-12.

22. Neagoe OC, Ionica M, Mazilu O. Use of methylene blue in the prevention of recurrent intra-abdominal postoperative adhesions. J Int Med Res 2018:46:504-10.

23. Kalaycı MU, Eroğlu HE, Kubilay D, Soylu A, Sancak $\mathrm{B}$, Uğurluoğlu $\mathrm{C}$, et al. The effects of methylene blue on adhesion formation in a rat model of experimental peritonitis. Ulus Travma Acil Cerrahi Derg 2011;17:205-9.

24. Privistirescu AI, Sima A, Duicu OM, Timar R, Roșca MG, Sturza A, et al. Methylene blue alleviates endothelial dysfunction and reduces oxidative stress in aortas from diabetic rats. Can J Physiol Pharmacol 2018;96:1012-6.

25. McCartney SL, Duce L, Ghadimi K. Intraoperative vasoplegia: methylene blue to the rescue! Curr Opin Anaesthesiol 2018;31:43-49.

26. Peck FH, Bücher CA, Watson JS, Roe A. A comparative study of two methods of controlled mobilization of flexor tendon repairs in zone 2. J Hand Surg Br 1998;23:41-5.

27. Hatanaka H, Manske PR. Effect of the cross-sectional area of locking loops in flexor tendon repair. J Hand Surg Am 1999;24:751-60.

28. Fatemi MJ, Shirani S, Sobhani R, Lebaschi AH, Gharegozlou MJ, Bagheri T, et al. Prevention of Peritendinous Adhesion Formation After the Flexor Tendon Surgery in Rabbits: A Comparative Study Between Use of Local Interferon- $\alpha$, Interferon- $\beta$, and 5-Fluorouracil. Ann Plast Surg 2018;80:171-5. 